\title{
Determination the Influence of Load-rate on Strain and Spring-back Magnitude for Titanium Alloy by means of Numerical Simulation
}

\author{
David Koreček, Pavel Solfronk, Jiří Sobotka, Michaela Kolnerová \\ Faculty of Mechanical Engineering, Technical University of Liberec. Studentská 2, 46117 Liberec. Czech Republic. E- \\ mail: david.korecek@tul.cz,pavel.solfronk@tul.cz,jiri.sobotka@tul.cz,michaela.kolnerova@tul.cz
}

\begin{abstract}
Nowadays, when there is strong tendency to still accelerate production process and thus save time and money, is very necessary to take into account influences of the individual process parameters on forming process. Another tendency tries to reduce weight of parts at keeping the required mechanical properties. These aspects lead also to utilization numerical simulations for modelling processes and materials with the specific utility properties. This paper deals with the influence of load-rate (thus also strain-rate) on the own process of metal sheet forming (namely U-die bending) - in light of both achieved deformation and subsequent spring-back of material. Field of titanium and its alloys application for the engineering industry is closely related especially with its suitable ration between strength and density. Deformation and subsequent spring-back was investigated by the numerical simulation in the software PAM-STAMP 2G.
\end{abstract}

Keywords: Titanium, Strain-rate, Deformation of material, Spring-back, Numerical Simulation

\section{Introduction}

Utilization of titanium and its alloys in the industrial production has already found quite wide range of applications. Such reality is given mainly due to its favourable ratio between strength and density. In light of strength, titanium achieves similar magnitudes as high-strength steels, but has lower Young's modulus (cca. by 50\%). Due to low density and good mechanical properties can be titanium taken as almost ideal construction material. On the other hand, mainly due to its high price, titanium can be found especially in the aircraft industry and some special applications. But as was already mention before, titanium and its alloys can be found also in the automotive or another industry. $[1,2]$

Due to the nowadays trend still to accelerate, improve and predict the own production process on the one hand and subsequently to keep the most efficient economic aspects of production on the other hand, there are still greater requirements about applications pre-production methods, which can map the whole process before investment in needed devices and tools. In these cases, the use of numerical simulations of the given process is offered. This paper uses numerical simulations in the PAM-STAMP $2 \mathrm{G}$ software environment. The effect of load-rate (thus also strain rate) on the deformation abilities of tested material and subsequent spring-back of part after unloading was tested by the numerical simulation. In order to take into account the effect of the load-rate in the numerical simulation computational model, there were performed static tensile tests under chosen load-rates. After the material model was defined, own simulation of metal sheet forming process (here U-die bending) was done. The results from numerical simulation were compared with the real blank and its spring-back for the tested material - titanium alloy Ti-CP AMS4911 6Al-4V. [1, 2]

\section{Experimental tests}

Own experimental part of this paper consists of two major parts. Firstly, there is determination of important input data carried out by static tensile test under different load-rates and then the subsequent performing of numerical simulation that utilized quite new Vegter material model.

\subsection{Static tensile test}

Common static tensile test was performed to measure the basic mechanical properties of tested material. By means of this test there were determined the following quantities - proof yield strength $\mathrm{R}_{\mathrm{p} 0,2}$, ultimate strength $\mathrm{R}_{\mathrm{m}}$, uniform ductility $\mathrm{A}_{\mathrm{g}}$, total ductility $\mathrm{A}_{80 \mathrm{~mm}}$ and Young's modulus of elasticity E. [3,4]

Static tensile test was performed at the testing device TIRA Test 2300 that is equipped with integrated length gauge MFN-A-4-500. Own test evaluation was carried out in the environment of software LabNET. Test was done under three different load-rates $(5,50$ and 500 $\mathrm{mm} / \mathrm{min}$ ), because for proper definition in the numerical simulation was necessary to measure material characteristics for different load-rates. Results from the static tensile test, which were taken as arithmetic mean from 3 samples, are for the individual load-rates shown in Tab. 1. Corresponding engineering stress-strain curves (again for different load-rates) are subsequently shown in Fig. 1.

Nevertheless, for complete definition of the material model in numeric simulation there was also necessary to determine strength coefficient $\boldsymbol{C}$, strain hardening exponent $\boldsymbol{n}$ and offset of strain $\boldsymbol{\varphi}$. These values were obtained from fitting true stress/strain curves acc. to Krupkowsky (see equation 1) and are given in Tab. 2.

$$
\sigma=C \cdot\left(\varphi+\varphi_{0}\right)^{n}
$$

Where:

$C$ - strength coefficient [MPa],

$n$ - strain hardening exponent[-],

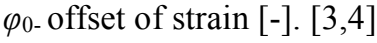


Tab. 1 Result of static tensile test for applied load-rates

\begin{tabular}{|c|c|c|c|c|}
\hline $\begin{array}{c}\text { Load-rate } \\
{[\mathrm{mm} / \mathrm{min}]}\end{array}$ & $\begin{array}{c}\boldsymbol{R}_{\mathbf{p} \mathbf{0}, \mathbf{2}} \\
{[\mathrm{MPa}]}\end{array}$ & $\begin{array}{c}\boldsymbol{R}_{\mathbf{m}} \\
{[\mathrm{MPa}]}\end{array}$ & $\begin{array}{c}\boldsymbol{A g}_{\mathbf{g}} \\
{[\%]}\end{array}$ & $\begin{array}{c}\boldsymbol{A} \mathbf{8 0 m m} \\
{[\%]}\end{array}$ \\
\hline 5 & 456.2 & 591.6 & 13.94 & 24.41 \\
\hline 50 & 489.6 & 609.8 & 11.36 & 21.91 \\
\hline 500 & 528.1 & 637.8 & 11.6 & 22.16 \\
\hline
\end{tabular}

Tab. 2 Results of fitting stress-strain curve-approximations constants acc. to Krupkowsky equation

\begin{tabular}{|c|c|c|c|c|}
\hline $\begin{array}{c}\text { Load-rate } \\
{[\mathrm{mm} / \mathrm{min}]}\end{array}$ & $\begin{array}{c}\boldsymbol{C} \\
{[\mathrm{MPa}]}\end{array}$ & $\begin{array}{c}\boldsymbol{\varphi} \\
{[-]}\end{array}$ & $\begin{array}{c}\boldsymbol{\varphi} \\
{[-]}\end{array}$ & $\begin{array}{c}\boldsymbol{\varphi}_{0} \\
{[-]}\end{array}$ \\
\hline 5 & 941.305 & 0.1665 & 0.12409 & 0.0125 \\
\hline 50 & 977.294 & 0.1726 & 0.10581 & 0.0212 \\
\hline 500 & 1061.765 & 0.2018 & 0.10322 & 0.0366 \\
\hline
\end{tabular}

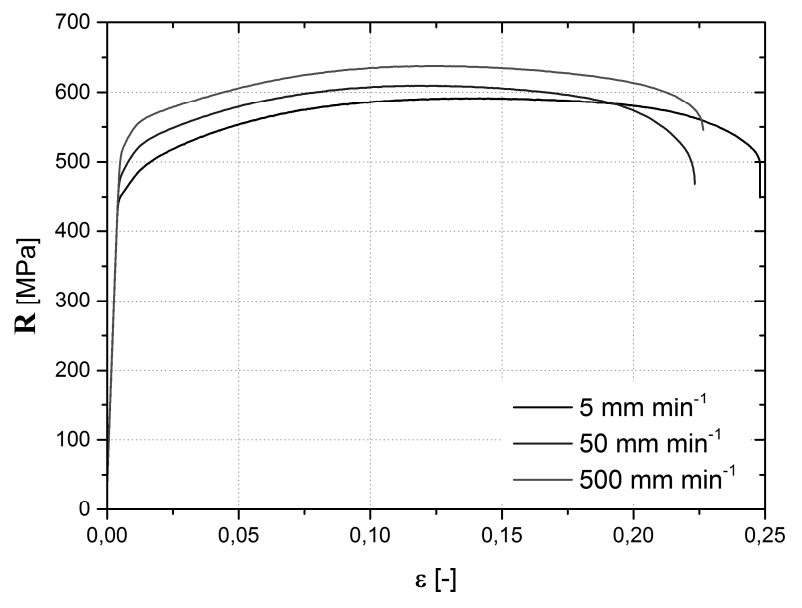

Fig. 1 Engineering stress-strain curves of tested material for different load-rates

\subsection{U-die bending process}

Just to verify the validity of results computed from numerical simulation, there was necessary to produce the real blank from the titanium alloy. Because of that there was made blank by means of the U-die bending technology. This part was produced by the simple bending tool consisting from bending punch, bending die and blank-holder. Own bending process was performed at device TIRA Test 2300, where is possible to control feed rate of bending tool. Individual blanks were produced under different load-rates - namely 5, 50 and 500 $\mathrm{mm} / \mathrm{min}$. After their own production, there was needed to determine their contour after spring-back. Such contour of real blanks was obtained by means of $3 \mathrm{D}$ coordinate measuring device SOMET XYZ 464 with involved software TANGO!3D.

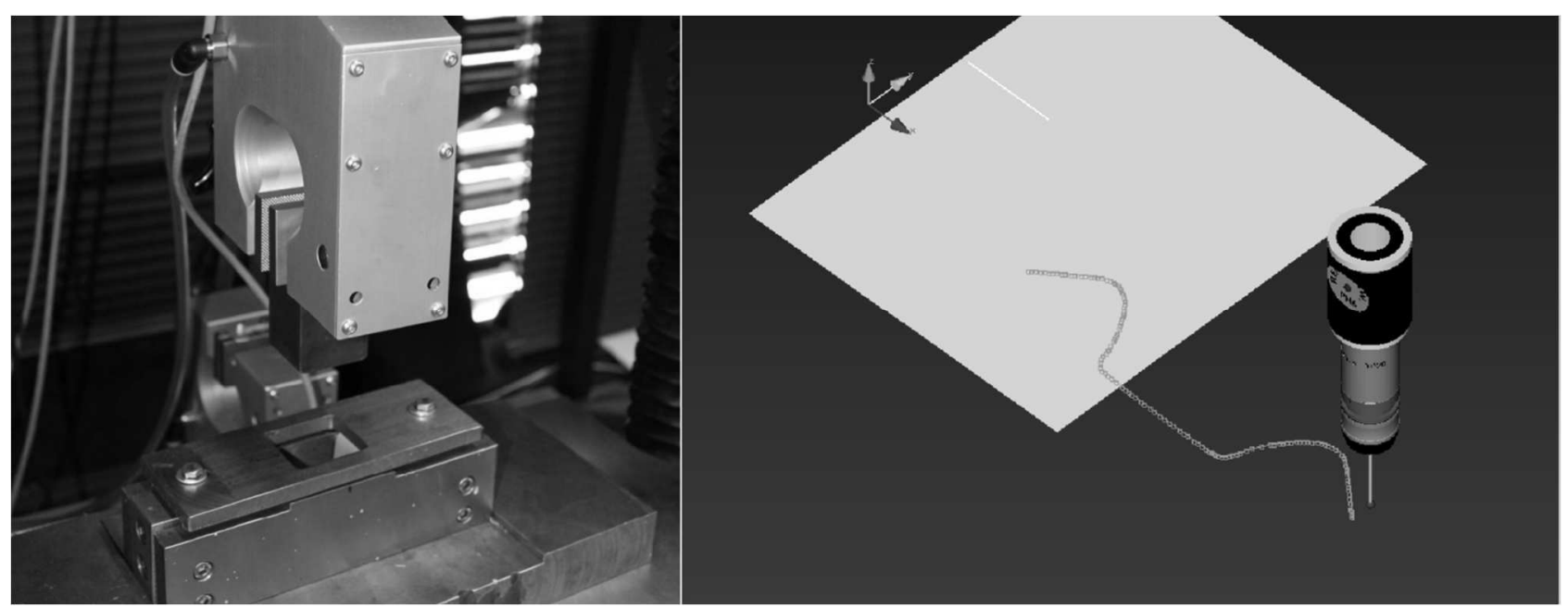

Fig. 2 Arrangement of the U-die bending and measurement of contour after bending

\section{Numerical simulation}

As a basic tool of numerical simulations and computations there are numerical methods for mechanics of deformable bodies, where is basically used final element method (FEM). This method is considered to be as the most efficient method of the mathematical modelling that is used in the metal forming simulation processes. In this paper was used software PAM-STAMP $2 \mathrm{G}$, which is specialized CAE software for simulation mainly the metal forming processes, where is CAD model of tool automatically transferred on the computational mesh CAE model. Such mesh of the blank (sheet) is generated in the environment of graphical pre-processor together with required boundary, contact and loading conditions of own solving. [5,6]

Nevertheless, to achieve the maximal efficiency of numerical simulation and to ensure the highest validity of results, there is necessary to know and absolutely precisely defined geometrical proportions of forming tool 
and contour of sheet intended for forming. As an another aspect for precise course of simulation there is perfect setting of the boundary conditions and process parameters for the simulated process.

In this paper was by means of the numerical simulation in software PAM-STAMP $2 \mathrm{G}$ both simulated and performed the metal forming process - to be specific U-die bending of sheet. Moreover, there wasn't performed only numerical simulation of bending, but there was also computed magnitude of subsequent springback of tested material.

\subsection{Definition of the Vegter material model}

Material model termed as Vegter with isotropic hardening of material (further just Vegter model) was used in the numerical simulation in the environment of software PAM-STAMP 2G. The Vegter model is suitable for anisotropic material. However, it requires more complicated measurement of material properties in tension, compression and shear. To define this material model, there is needed to define not only material properties and characteristics of used alloy, but also to determine control points of ellipse, which are measured from the material mechanical tests. $[5,6]$

To define the Vegter model with isotropic hardening of material is necessary to determine quantity as follows:
- Young's modulus in tension E

- Poisson's ratio $\mu$

- Density $\rho$

- Static tensile test for rolling directions $0^{\circ}, 45^{\circ}$ a $90^{\circ}$ (mean hardening curve in the relevant directions)

- Normal anisotropy coefficients for rolling directions $0^{\circ}, 45^{\circ}, 90^{\circ}$

- Plain strain tensile test

- $\quad$ Bulge test (to define multiaxial state of stress)

This material model has been already fitted within the cooperation with company MECAS ESI Ltd.

To determine the influence of different load-rates on the forming process and subsequent spring-back of part in the numerical simulation, there was needed to involve into the material model other parameter that characterizes strain rate. The common static tensile test was performed to define these strain rates characteristics in the Vegter model, to be specific the following load-rates were used: 5,50 and $500 \mathrm{~mm} / \mathrm{min}$. The own definition of material model in the software PAM-STAMP is subsequently shown in Fig. $3[5,6]$.



Fig. 3 Definition of the material model in PAM STAMP $2 G$

\subsection{Definition of the FEM project}

To define numerical simulation in the environment of software PAM-STAMP $2 \mathrm{G}$, there is firstly needed to import individual parts of tool, which will realize the metal forming process. Moreover there is necessary to import contour of sheet as deformable element. These parts of bending tool (bending die and punch) were created in software CATIA V5 and their geometry corresponds to the real bending tool geometry. By this tool was also produced the real blank. Gradual import of bending die, bending punch, blank and blank-holder is shown in Fig. 4. 

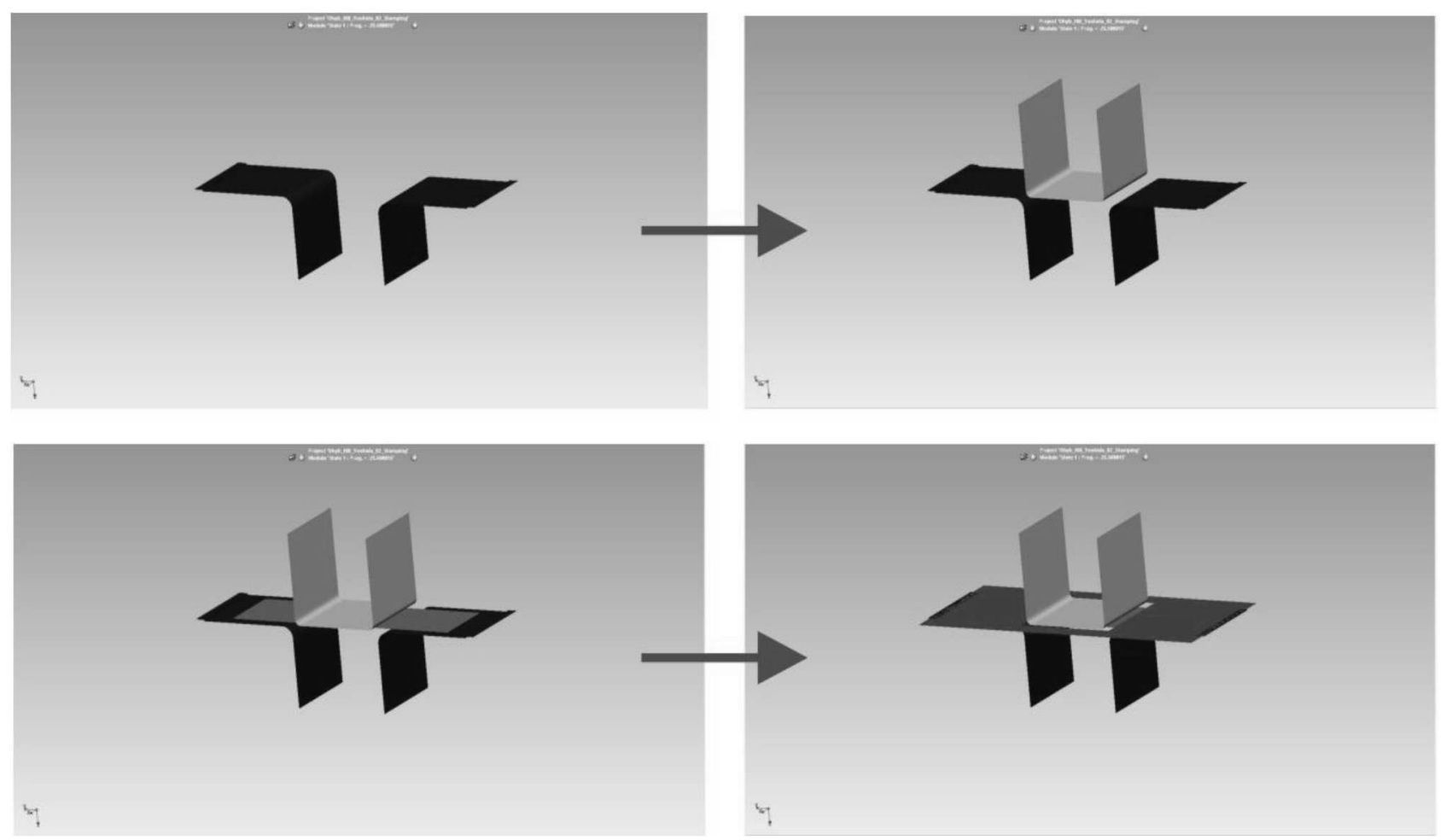

Fig. 4 Import of CAD tool into the software PAM-STAMP $2 G$

After import of tools, definition of deformable element (tested alloy) and adjustment of individual numerical simulation parameters was performed the own computation acc. to selected Vegter material model. Firstly, there was simulated own bending process and after tool deactivating, spring-back of material was computed as well. Final contours of sheets after bending process and subsequent spring-back is shown in Fig. 9.

\section{Overview of results}

Final contours from numerical simulation after material spring-back and contours of real blank are shown in the following figures. In Fig. 5 is shown graphical comparison of the final contours from numerical simulation for individual load-rates as following: red load-rate $5 \mathrm{~mm} / \mathrm{min}$, green - load-rate $50 \mathrm{~mm} / \mathrm{min}$ and blue for $500 \mathrm{~mm} / \mathrm{min}$.



Fig. 5 Comparison of sheet contours from numerical simulation for load-rates 5, 50 and $500 \mathrm{~mm} / \mathrm{min}$

In Fig. 6 is shown comparison of the final real sheet contours for the individual load-rates. There is used the same color indication as in the previous case (red -5 $\mathrm{mm} / \mathrm{min}$, green $-50 \mathrm{~mm} / \mathrm{min}$ and blue $-500 \mathrm{~mm} / \mathrm{min}$ ).

Fig. 7 shows the comparison of the final real sheet contours for the individual load-rate with the final contours computed from the numerical simulation. Real sheet contours have again the same color indication (red -5 $\mathrm{mm} / \mathrm{min}$, green $-50 \mathrm{~mm} / \mathrm{min}$ and blue $-500 \mathrm{~mm} / \mathrm{min}$ ) and contour from numerical simulation is shown in black.

The gradual deformation of the stamping process made by PAM-STAMP $2 \mathrm{G}$ numerical simulation environment is shown in Fig. 8. 




Fig. 6 Comparison of real sheet contours for load-rates 5, 50 and $500 \mathrm{~mm} / \mathrm{min}$

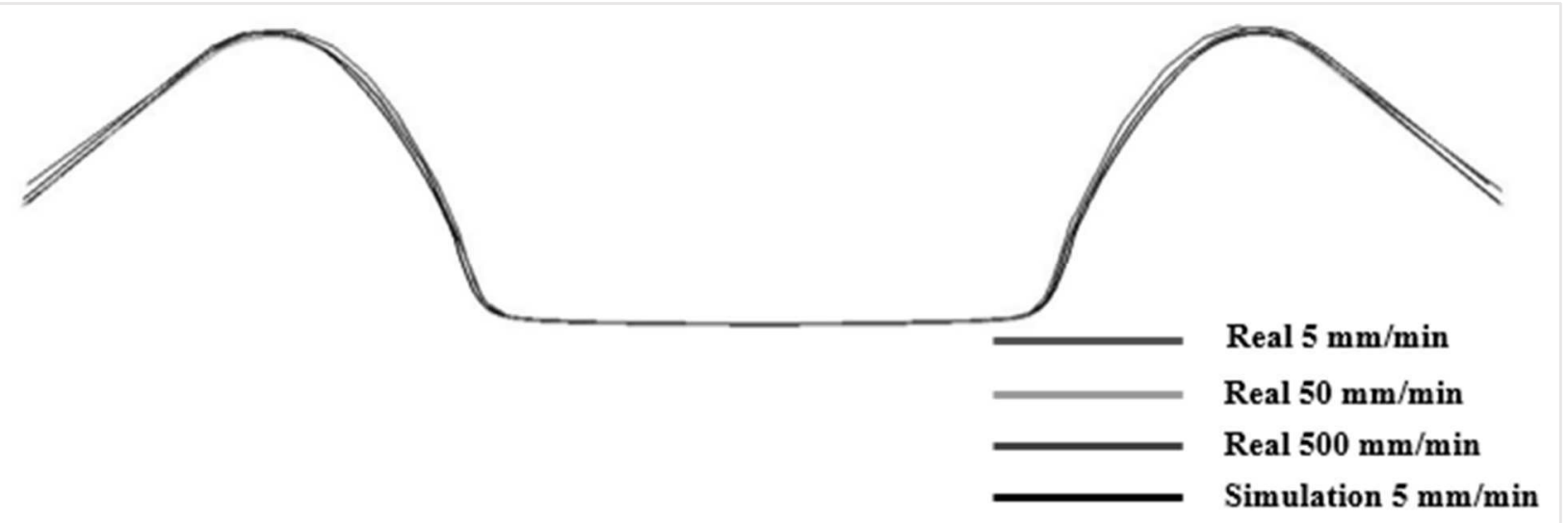

Fig. 7 Comparison of real sheet contours for load-rates 5, 50 and $500 \mathrm{~mm} / \mathrm{min}$ and sheet contours from numerical simulation

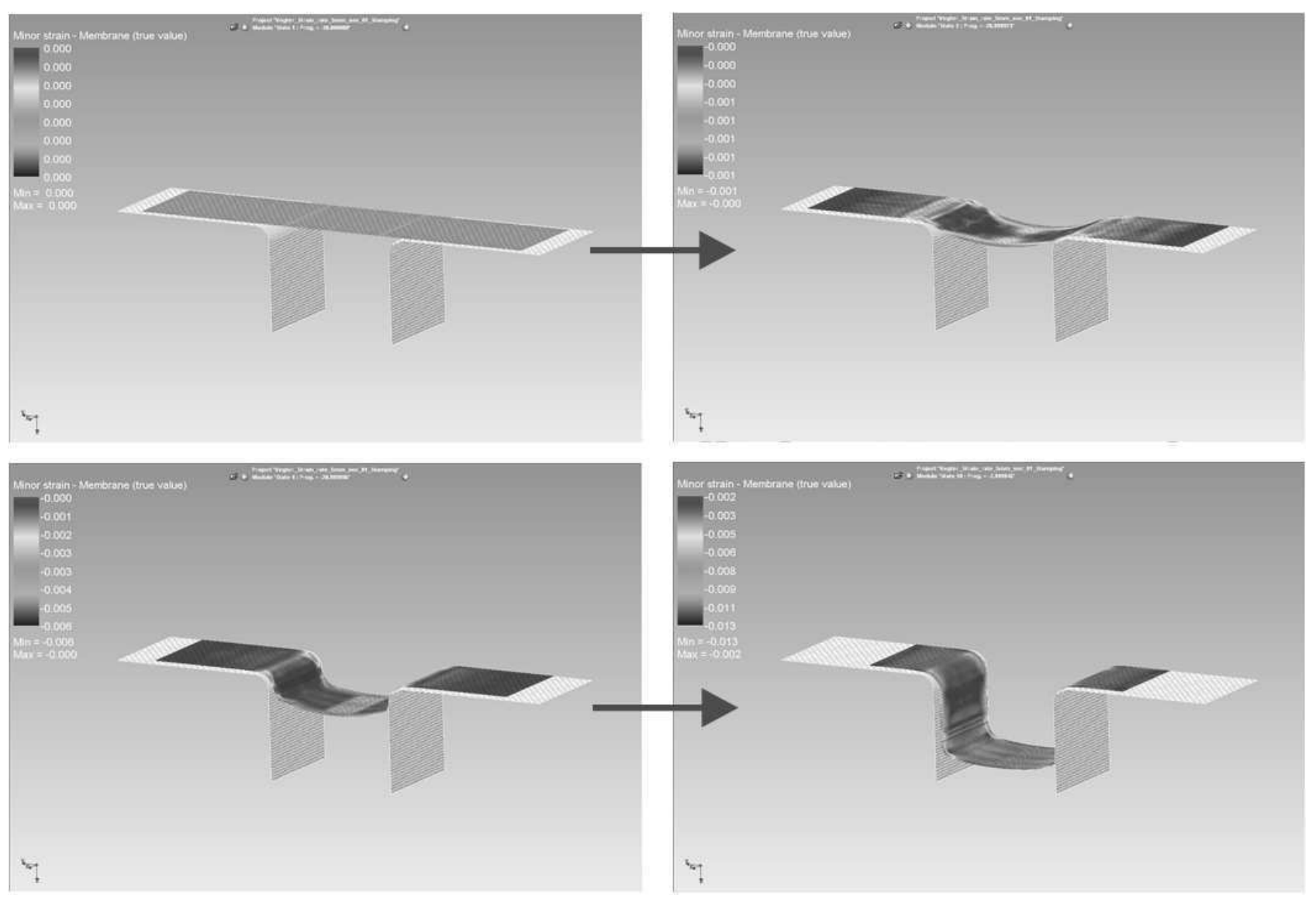

Fig. 8 Gradual deformation of the stamping process in numerical simulation 


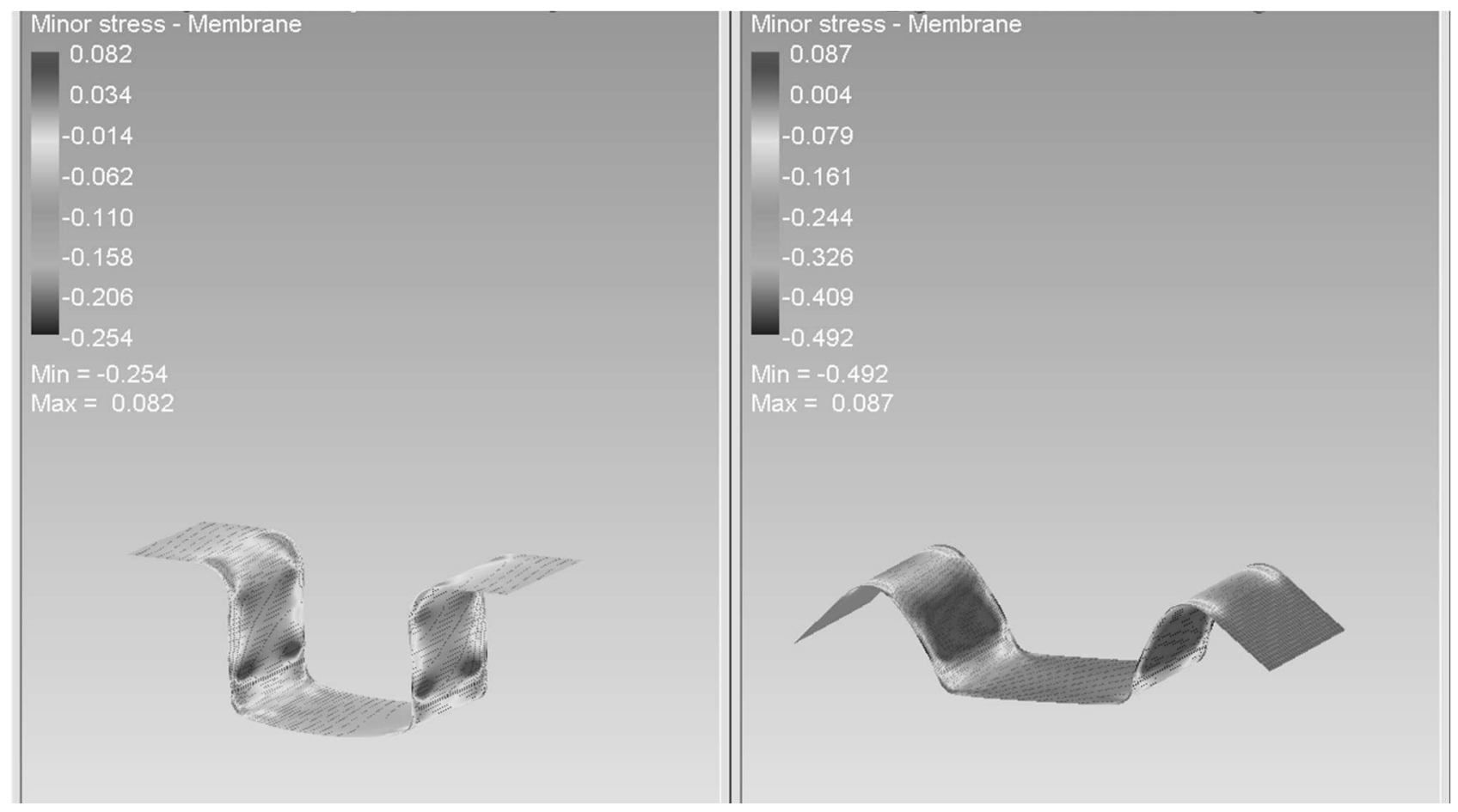

Fig. 9 Sheet contour before spring-back (left) and after spring-back (right)

In Fig. 9 is shown final contours of sheets after bending process and subsequent spring-back in the numerical simulation environment of software PAM-STAMP 2G.

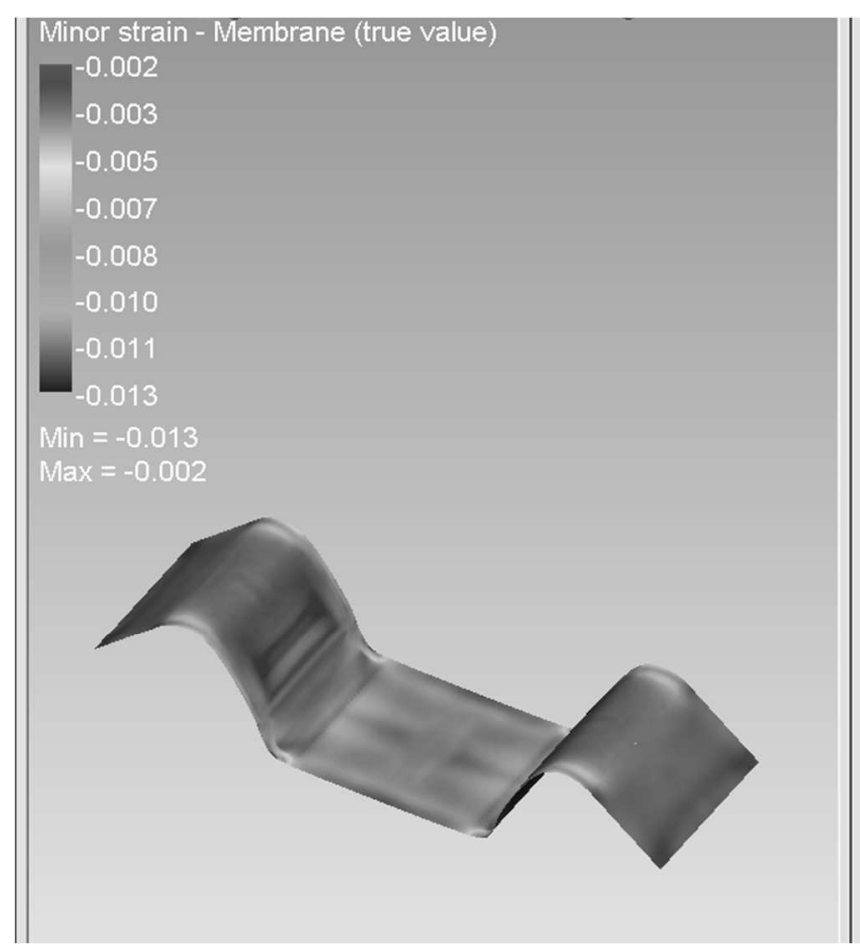

In Fig. 10 is graphically shown distribution of strain in blank for the individual load-rate in the numerical simulation environment of software PAM-STAMP 2G.

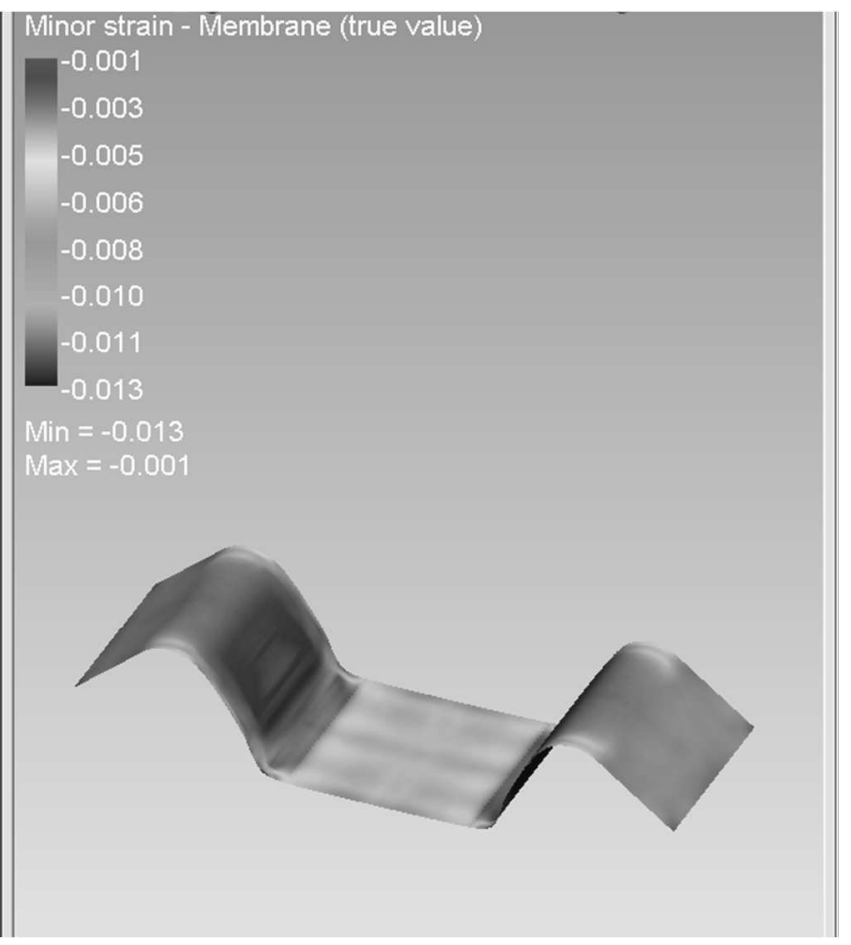

Fig. 10 Distribution of strain in blank for load-rate $5 \mathrm{~mm} / \mathrm{min}$ (left) and $500 \mathrm{~mm} / \mathrm{min}$ (right)

\section{Conclusion}

This article investigated the influence of load-rate on the deformation course and magnitude of spring-back. This problem was solved via numerical simulation in software PAM-STAMP 2G. Using the numerical simulation, there was investigated the course of sheet metal forming process, to be specific U-die bending and its subsequent spring-back due to elastic deformation. As a trend in the industry today is the search for and application of new materials to improve component properties, weight reduction, corrosion resistance and so on, own research was applied to the titanium alloy Ti-CP AMS4911 6Al$4 \mathrm{~V}$. 
So-called Vegter material model was used for numerical simulation. Moreover, material characteristics for the individual load-rates were added into this model. These characteristics were obtained from the static tensile test at selected load-rates: 5, 50 and $500 \mathrm{~mm} / \mathrm{min}$. In order to verify the numerical simulation results validity, a real stamping (blank) was also produced, which corresponded to the numerical simulation by its own production process. The contour of this blank was further compared with the resulting contour obtained from the numerical simulation.

When comparing the resulting contours from the numerical simulation (see Fig. 6), there is evident that apart from the slight variations in the contour obtained at loadrate $500 \mathrm{~mm} / \mathrm{min}$, the differences between the contours for applied load-rates are practically negligible. Small deviations are achieved by comparing the contours of the real forming process for the selected load-rates (see Fig. 7). Comparing the results of the real process and the numerical simulation, minor deviations of the resulting contour of the blank are again achieved. Nevertheless, the results of the numerical simulation quite accurately describe the selected forming process and can be considered as very beneficial. Fig. 8 shows the course of deformation during the forming process and Fig. 9 shows stress distribution on the blank right before its removing from tool and subsequent spring-back. Various small changes in stress distribution are also shown for different load-rates, this fact is illustrated in Fig. 10. The results obtained at different load-rates revealed minor differences and deviations which should be verified by further research for different load-rates, eventually to use a more complex material model of numerical simulation that takes into account the kinematic hardening of material.

\section{Acknowledgement}

This publication was written at the Technical University of Liberec as part of the Student Grant Contest "SGS
21121" with the support of the Specific University Research Grant, as provided by the Ministry of Education, Youth and Sports of the Czech Republic in the year 2018.

\section{References}

[1] FOUSOVÁ, M., DALIBOR, V., KUBÁSEK, J. (2016) Titanium Alloy Ti-6Al-4V Prepared by Selective Laser Melting (SLM). pp. 691-697. Manufacturing Technology, Volume 16.

[2] ASTARITA, A., PRISCO, U. (2017) Tensile Properties of Hot Stretch Formed Ti-6Al-4V Alloy Component for Aerospace Applications. pp. 141-147. Manufacturing Technology, Volume 17.

[3] ASM HANDBOOK. Volume 8 - Mechanical Testing and Evaluation. 10th ed. Materials Park: ASM International, 2000. s. 998. ISBN 0-87170389-0.

[4] HOSFORD, W.F., CADDEL, R. Metal Forming (Mechanics and Metallurgy). 3rd ed. New York: Cambridge University Press, 2007. s. 312. ISBN 978-0-521-88151-0.

[5] SHUN-LAI, Z., et al. (2013). Evaluating the significance of hardening behavior and unloading modulus under strain reversal in sheet springback prediction. International Journal of Mechanical Sciences, December 2013, Vol. 77, pp 194-204. ISSN 0020-7403.

[6] TAHERIZADEH, A., et al. (2009). Finite element simulation of springback for a channel draw process with drawbead using different hardening models. International Journal of Mechanical Sciences, April 2009, Vol. 51, No. 4., pp 314-325. ISSN 0020-7403. 